\title{
The Art and Science of Medicine: A Journey Through Time, a Prelude to Its Future
}

Anil Harrison, MD

Having trained in medicine during times when resources were limited and investigative opportunities were scarce, the science of medicine depended on the art of conducting a diligent history and physical examination followed by critical thinking in arriving at a differential diagnosis. This was followed by choosing a few pertinent investigative studies to help finding a conclusion, the diagnosis.

About 25 years later, as an Associate Program Director of an internal medicine residency program, I find physicians relying on a vast plethora of investigative studies while attempting to discern the etiology of a patient's illness. The overreliance and ease of ordering tests are causing health care costs to spiral out of control, while the art of critical thinking and choosing investigative studies wisely are taking a back seat. With the concept of humaneness unfortunately becoming a thing of the past as well, it would not be surprising if health care is taken over in entirety by technology.

I, for one, value the benefits of technology and cannot emphasize enough how well it has filled many voids-from spitting out atherosclerotic cardiovascular disease risk scores or fracture risk assessment scores in a jiffy to performing complicated robotic surgeries. My skepticism arises from our underutilization of critical thinking and an overdependence on technology.

Our training in medicine includes the importance of having an appropriate demeanor, tone, and curiosity of a patient's ailment; conducting a thorough history and physical examination; having an inquisitive and open mind to think critically; and delivering care with empathy. To do so, a physician is trained to depend on utilizing his or her special senses of sight, sound, and touch to sniff out the query.

Medical accessories such as stethoscopes, reflex hammers and ophthalmoscopes serve as extensions of ourselves to reach deeper into the mystery, while the enthusiastic mind works arduously toward determining the possibilities of a person's illness, with investigative studies chosen conservatively and wisely to help conclude the enigma, the diagnosis-the

\section{AFFILIATIONS:}

Internal Medicine Department, Touro University Medical Group, Stockton, California

\section{CITATION:}

Harrison A. The art and science of medicine: a journal through time, a prelude to its future. Consultant. Published online January 13, 2022. doi:10.25270/con.2022.01.00002

Received August 27, 2021. Accepted September 22, 2021.

\section{DISCLOSURES:}

The authors report no relevant financial relationships.

\section{CORRESPONDENCE:}

Anil Harrison, MD, 1805 North California Street, Suite 201, Stockton, CA 95204 (Anil.Harrison@mytumg. org)

art and science of medicine. And, unfortunately, our patients suffer when we cannot conduct a good physical examination.

With time, science and technology have progressed, creating more opportunities to think better in narrowing the possibilities and helping improve patient care. Investigative tests and therapeutics are being constantly replaced with newer and "better" ones, akin to the ever-changing models of smartphones. Although patient outcomes and longevity have improved, our reliance and overindulgence in investigative studies have caused health care costs to soar.

With technology's ability to gather data, it would not surprise me if technology takes over patient care in entirety, with better patient outcomes and lower health care costs. However, technology should not dehumanize medicine; instead, it should be accompanied by ethical and deontological principles, reinforced by medical schools where teaching with values focused on a patient's wellbeing and resolution of disease. ${ }^{2}$ Humanizing medicine, with more attention on treating beyond an illness, needs to be revisited-something that technology cannot replace.

I recently walked into an examination room and saw my patient George, who had been in congestive heart failure during his last visit, with an elevated jugular vein distention, an audible left ventricular S3, and moderate edema. Today he felt better, and his abnormal clinical findings had resolved. I noticed the glint in George's eyes and felt his excitement of looking forward to holding his newborn grandson. I advised him on getting some basic laboratory workup 
conducted, shook his hand, and returned to my office to reflect on my well-used medical accessories.

\section{References}

1. Boodman SG. Patients lose when doctors can't do good physical exams. Medscape. Published online May 20, 2014. https://www.medscape.com/viewarticle/825442\#: :text=Both\%20cases\%20 reflect\%20a\%20phenomenon,to\%20 make\%20an\%20accurate\%20diagnosis

2. Cruz Senzano AA, Cruz Rocha CM.

Medicine in 2030: Should we prepare for the future of medicine? Isr Med Assoc J. 2019;21(8):563-564. https://www.ima.org.il/ FilesUploadPublic/IMAJ/0/378/189329.pdf 